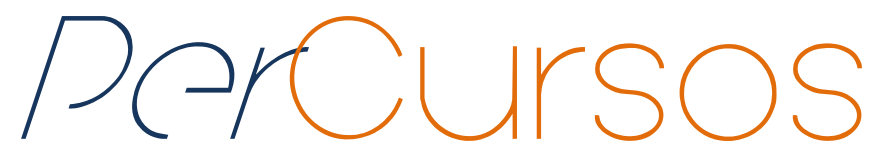

\title{
Impressos Virtuais: estudos de caso e reflexões sobre História Digital e História Pública'
}

\section{Resumo}

Este trabalho tem como proposta a análise de três sites de instituições voltadas à pesquisa na área da história de imprensa e do jornalismo. Os portais analisados foram o site do LABHOI/UFF, o Portal do Centro de Documentação e Memória DELFOS, da PUCRS, e o Portal do Centro de Cultura e Memória do Jornalismo, vinculado ao Sindicato dos Jornalistas Profissionais do Rio de Janeiro. Procurou-se abordar neste texto a aproximação entre a função destes portais enquanto espaço de divulgação e as perspectivas da História Oral e História Pública. Pela observação dos sites destacados apresentou-se esta proposta de estudo, destacando as iniciativas de divulgação histórica associadas ao uso de novas linguagens e suportes mediatizados. O trabalho ainda estende suas reflexões à prática do historiador contemporâneo no que se refere ao tratamento de fontes e as concepções da história pública e histórica digital.

Palavras-chave: História Oral; Imprensa; Portais da WEB; Sites da Web.
Igor Lemos Moreira

Graduando em História pela

Universidade do Estado de Santa

Catarina - UDESC.

Brasil

igorlemoreira@gmail.com

Márcia Ramos de Oliveira

Doutora em História pela

Universidade Federal do Rio

Grande do Sul - UFRGS.

Professora da Universidade do

Estado de Santa Catarina -

UDESC

Brasil

marciaroliveira50@gmail.com

\section{Para citar este artigo:}

MOREIRA, Igor Lemos; OLIVEIRA, Márcia Ramos de. Impressos Virtuais: estudos de caso e reflexões sobre História Digital e História Pública. Revista PerCursos, Florianópolis, v. 17, n.34, p. 52 - 67, maio/ago. 2016.

\section{DOI: $10.5965 / 1984724617342016052$}

http://dx.doi.org/10.5965/1984724617342016052

\footnotetext{
${ }^{1}$ Algumas reflexões aqui apresentadas foram apresentadas em outro texto enviado para o Encontro Estadual de História da ANPUH em 2016. Projeto de Pesquisa "A Experiência dos Laboratórios de História Oral e Imagem e Som diante da História Pública: Estudos de Caso e Reflexões (2014/2015)", com apoio da Universidade do Estado de Santa Catarina - UDESC.
} 


\title{
Virtual printed : case studies and reflections on Digital History and Public History
}

\begin{abstract}
This paper is to analyze one proposal, tree Institutions sites focused on research in the area of press history and journalism. The portals analyzed the site Were do LABHOI/UFF, the Portal of the Center for Documentation and Memory DELFOS/PUCRS, and the Portal of the Center for Culture and Memory of Journalism, linked the Union of Professional Journalists of Rio de Janeiro. We tried to address this text the Rapprochement between the function of these portals as Disclosure space and how Prospects of Oral History and Public History. Note the featured sites presented this proposal to study, highlighting how Historical Disclosure Initiatives Associated By Using New Languages and mediated Media. The work extends still your reflections historian practice in refere what is the treatment of sources and how conceptions of public history and digital Historical.
\end{abstract}

Keywords: Oral History; Press; Web Portals; Web Sites. 
Ao refletirmos sobre a História da Imprensa, estamos nos referindo a uma alternativa recente quanto às novas formas de narrar a história, que neste caso, vinculamse diretamente à perspectiva dos profissionais de comunicação na construção de uma memória do seu campo de atuação profissional. Sob tal perspectiva, entendemos a reflexão da intervenção do historiador no tratamento de fontes da imprensa (revistas, jornais, televisão, rádio), trazendo ao debate metodológico a perspectiva de Jacques Le Goff quanto a observar tais vestígios do passado enquanto documentos históricos (LE GOFF, 2003),

o documento não é qualquer coisa que fica por conta do passado, é um produto da sociedade que o fabricou segundo as relações de forças que aí detinham o poder. Só a análise do documento enquanto monumento permite à memória coletiva recuperá-lo e ao historiador usá-lo cientificamente, isto é, com pleno conhecimento de causa. (LE GOFF, 2003. p. 545)

Uma revisão bibliográfica aponta para autores como Nelson Wernek Sodré, em História da Imprensa (1977), e Juarez Bahia, na obra Jornal, História e Técnica (1990), destacados de cânones da história da imprensa no Brasil. Focando em leituras historiográficas mais factuais e processuais, tais obras podem ser consideradas na atualidade referências críticas e complementares aos interessados no campo da história da comunicação. Na década de 1980, autoras como Maria Helena Capelato e Maria Ligia Prado trouxeram contribuições fundamentais para a análise historiográfica, vinculadas à perspectiva da História Social. Tais abordagens apontavam para a observação dos jornais como possíveis fontes de pesquisa para a compreensão dos processos históricos em curso, com destaque aos acontecimentos recentes. Em momento posterior, pode ser destacada a extensa produção de Marialva Barbosa, pesquisadora oriunda do campo do jornalismo, porém com evidente aproximação do campo historiográfico em sua produção, desenvolvendo, neste caso, um estudo de caráter interdisciplinar, a exemplo da proposta de uma História Cultural da Imprensa. 
Considerando esta linha de abordagem, é preciso compreender a interação de múltiplos agentes a partir da integração dos jornais enquanto elementos de uma rede ou circuito comunicacional. Muito importante destacar a necessidade de compreensão que se estabelece entre a produção dos textos, em suas características materiais, junto ao universo de recepção, evidenciando as relações entre produtores e leitores, as representações de mundo, a elaboração de informações... Neste caso, aproximando a articulação de campos de análise como a Teoria da História, a História da Comunicação, a História do Livro e da Leitura, a História das Práticas Jornalísticas e dos Eventos, entre outros. Uma História Cultural da Imprensa é pensada como um campo múltiplo, com diversos fatores em cruzamento. Segundo Barbosa (2004, p. 3):

Se esse é o parâmetro mais genérico a que podemos nos referir e que nos induz a considerar no trabalho de escritura da história, sempre, as categorias, tempo, espaço e grupos sociais, quando se fala particularmente de uma história da imprensa, há que se considerar a noção de sistema que é o cerne mesmo das relações comunicacionais. Assim, falar em história da imprensa é falar em processos comunicacionais e das intricadas relações que se desenvolvem em torno desse sistema de comunicação.

Um ponto que vem contribuindo para as possibilidades de trabalhos nesta perspectiva é a disponibilização de fontes para além dos produtos finais, os impressos, possibilitando acesso às cartas e correspondências dos editores, diários de jornalistas... Vivemos, como aponta François Hartog (2014), um momento de emergência de preocupações relacionadas à preservação do passado, experenciando, assim, um processo denominado como "onda patrimonial". Tais constatações espelham-se nos conflitos que marcaram o século XX, a partir dos quais a sociedade ocidental, especialmente, viu alterarem-se as relações com o tempo.

Segundo Reinhart Kosselleck (2006) nossas percepções sobre o tempo são construídas através de jogos entre o passado, presente e futuro. Como coloca o autor, a concepção de tempo histórico resulta das tensões entre os "espaços de experiência", constituídos pelo passado interiorizado e as projeções de futuro projetadas como 
“horizontes de expectativa". A experiência do trauma, enquanto parte da experiência histórica, a exemplo da Primeira Guerra Mundial, desencadeou segundo Hartog (2014), nossa concepção atual sobre a história, ou nosso "regime de historicidade", a partir do qual o futuro passou a ser diretamente observado pela perspectiva do passado. Pois, "se, em primeiro lugar ele foi mais futurista do que presentista, terminou mais presentista do que futurista" (HARTOG 2014, p. 140). Com isso, novas tentativas de identificação, produção e preservação de fontes foram surgindo, diante de uma outra compreensão sobre o documento histórico e especialmente sobre a divulgação da produção historiográfica e o acesso às fontes e acervos de memória.

A partir destas colocações iniciais, apresentamos neste trabalho algumas considerações sobre o desenvolvimento do Projeto de Pesquisa "A Experiência dos Laboratórios de História Oral e Imagem e Som diante da História Pública: estudos de caso e reflexões (2014/2015)", que possibilitou a observação e caracterização de elementos relativos a plataformas digitais e à disponibilização de fontes e acervos, e especialmente da produção histórica salvaguardada nos portais consultados. Neste sentido, pretendemos apresentar neste texto uma breve descrição e análise sobre três portais vinculados à memória histórica e sua disponibilização no Brasil, de forma qualitativa, como exercício de reflexão desenvolvido no citado Projeto. Os sites observados são vinculados a três instituições: 1) Laboratório de História Oral (LABHOI)², no Departamento de História da Universidade Federal Fluminense (UFF); 2) Centro de Memória DELFOS, da Pontifícia Universidade Católica do Rio Grande do Sul (PUCRS)33; e, 3) o Portal do Centro de Cultura e Memória do Jornalismo (CCMJ/RJ) ${ }^{4}$, criado pelo Sindicato dos Jornalistas do Rio de Janeiro.

\section{História Digital e o objetivo do projeto}

Neste artigo, apresentamos resultados parciais do Projeto mencionado, que encontra-se em desenvolvimento desde 2014 vinculado, enquanto linha de abordagem, à

\footnotetext{
${ }^{2}$ Disponível para acesso através do link: <http://www.labhoi.uff.br>.

${ }^{3}$ Disponível para acesso através do link: <http://www.pucrs.br/delfos/?p=resende>.

${ }^{4}$ Disponível para acesso através do link: <http://www.ccmj.org.br>.
} 
experiência adquirida no Laboratório de Imagem e Som (LIS/FAED) ${ }^{5}$ da Universidade do Estado de Santa Catarina (UDESC). Destacam-se como objetivos centrais do Projeto a análise de distintas atuações dos Laboratórios de História Oral e Imagem e Som nas instituições brasileiras, tendo como parâmetro de observação a divulgação de dados e acervos em suas plataformas digitais e sites. Tal conteúdo histórico e/ou historiográfico disponibilizado vem sendo analisado sob a perspectiva de abordagens ancoradas nos conceitos de História Digital, História Pública e História do Tempo Presente. Considerando tais premissas como atualizações do ofício do historiador contemporâneo, a preocupação em estender os resultados do trabalho de cunho historiográfico constitui-se o ponto em que a divulgação do conhecimento desta área aproxima-se do universo da comunicação, e até certo ponto, compartilha de interpretações relacionadas à História (Cultural) da Imprensa, ou mesmo à História Social da Mídia. Basicamente, a pesquisa empírica sobre os sites apontados foi destinada a identificar como os laboratórios e centros de memória articularam-se com as novas linguagens digitais e técnicas na disponibilização dos conteúdos de cada área. Para além da palavra escrita e das textualidades, buscou-se observar as relações estabelecidas com o entorno social, além da esfera acadêmica. Como destaca Bresciano (2010, p. 1),

La Historia Oral, en cuanto subcampo disciplinario, no permanece ajena a esas transformaciones, en la medida en que ciertos cambios tecnológicos introducen modalidades originales de recabar, procesar, analizar y difundir testimonios orales, que inciden en el plano heurístico, hermenéutico, organizativo y discursivo de la propia especialización disciplinaria.

Em uma primeira etapa, realizamos um inventário através da plataforma de pesquisa Google, dos Laboratórios de Imagem e Som e/ou História Oral, listando sites e/ou plataformas digitais encontrados. Com esse levantamento, conseguimos relacionar, inicialmente, 14 Laboratórios de História Oral e/ou Imagem e Som nas cinco grandes regiões do Brasil, além de 11 Centros de Memória observados posteriormente. Nesta

\footnotetext{
${ }^{5}$ Disponível para acessoa através do link: <http://www.lis.faed.udesc.br/>.
} 
segunda etapa da pesquisa empírica, a busca estendeu-se também a Centros de Memória, buscando ampliar o escopo de observação. Para melhor sistematizar as informações, apresentamos o quadro conforme espaços identificados em cada uma das grandes regiões. ${ }^{6}$

\begin{tabular}{|c|c|c|}
\hline Região & $\begin{array}{l}\text { Portais (Laboratórios de Imagem e } \\
\text { Som e História Oral) }\end{array}$ & Acervo de Memória \\
\hline S & $\begin{array}{l}\text { - Laboratório de História Oral (Univille) } \\
\text { - LABHORAL (UFSC) } \\
\text { - Laboratório de Pesquisa em História } \\
\text { Oral (PUCRS) } \\
\text { - LAPIS (UFSC) } \\
\text { - LEDI (UEL) } \\
\text { - LIM (UDESC) }\end{array}$ & $\begin{array}{l}\text { - DELFOS - Espaço de Documentação } \\
\text { e Memória Social }\end{array}$ \\
\hline SE & $\begin{array}{l}\text { - LABHOI (UFF) } \\
\text { - Laboratório de História Oral } \\
\text { (CMU/UNICAMP) } \\
\text { - Laboratório de História Oral - LHO } \\
\text { (Univás) } \\
\text { - Núcleo de História Oral (UFMG) }\end{array}$ & $\begin{array}{l}\text { - Centro de Memória da Unicamp } \\
\text { (UNICAMP) } \\
\text { - Museu da Imagem e do Som (MIS- } \\
\text { SP) } \\
\text { - Museu da Imagem e do Som de } \\
\text { Campinas } \\
\text { - Museu da Imagem e do Som (RJ) }\end{array}$ \\
\hline CO & $\begin{array}{l}\text { - Laboratório de Estudos da Imprensa, } \\
\text { Imagem e Som - LEIIS (UFMS) }\end{array}$ & $\begin{array}{l}\text { - Museu da Imagem e do Som } \\
\text { (Campo Grande) } \\
\text { - CEPEDOM (Centro de Pesquisa e } \\
\text { Documentação em Memória- UEG) }\end{array}$ \\
\hline $\mathbf{N}$ & $\begin{array}{l}\text { - Laboratório de Imagem e Som - LABI } \\
\text { (UFAC) }\end{array}$ & $\begin{array}{l}\text { - Museu de Imagem e Som - MIS } \\
\text { (Amapá) } \\
\text { - Museu da Imagem e do Som do } \\
\text { Pará }\end{array}$ \\
\hline NE & $\begin{array}{l}\text { - Laboratório de História Oral (UFPE) } \\
\text { - Laboratório de História Oral e } \\
\text { Imagem-LABHORI (UERN) }\end{array}$ & $\begin{array}{l}\text { - Museu da Imagem e do Som do } \\
\text { Ceará - MIS (Ceará) } \\
\text { - Museu da Imagem e do Som de } \\
\text { Alagoas - MISA } \\
\text { - Centro de Documentação e } \\
\text { Memória Regional (CEDOC - UESC) }\end{array}$ \\
\hline
\end{tabular}

Quadro 1 - Relação de Portais e Acervos de Memória inventariados Fonte: Elaborado pelos autores, 2015.

\footnotetext{
${ }^{6}$ Essa etapa da Pesquisa contou, além dos autores desse artigo, com a participação do Acadêmico Lucas Txai Fonseca, bolsista de I. C. no mesmo Projeto, entre agosto de 2015 e fevereiro de 2016.
} 
Como evidenciado no quadro, as regiões Sul e Sudeste apresentaram um concetrado número de sites e plataformas, diante do maior concentração também de instituições acadêmicas e iniciativas de pesquisa. Em parte, a ampliação do escopo da pesquisa integrando os Centros de Memória deve-se a esta observação inicial do trabalho, quando se constatou que nestas regiões encontravam-se instituições acadêmicas de menor tradição quanto ao ensino superior, em oposição a outras áreas em que a concentração numérica das instituições era ampla. O que justificava, em grande medida, também o maior número de laboratórios e centros de pesquisa em regiões como - Sul e o Sudeste, e por consequência, dos sites/plataformas identificados. Tal constatação, no entanto, não pode ser considerada conclusiva quanto a afirmar-se que nestas regiões encontre-se a maior concentração numérica de pesquisadores e produções no campo da História Oral, e sim que nelas existem mecanismos de divulgações mais utilizados/acessado no ambiente virtual.

Entre outras observações, concluímos que os sites da região Sudeste possuem um número mais concentrado de mídias disponíveis para consulta online na íntegra, além de layouts mais diversificados e menos institucionalizados se comparados à região Sul, por exemplo. Nas regiões Norte e Nordeste,os meios de disponibilização e de divulgação das produções são mais "práticos” ou "comuns", a exemplo do uso ampliado de plataformas como o YouTube e o Blogger. Nestas regiões, o YouTube é o meio mais comum de disponibilização, o que também se verifica na maioria das produções brasileiras nestas plataformas, existindo laboratórios que usam apenas esse canal ao invés de desenvolver sites ou plataformas digitais próprios.

Em sua maioria, os sites possuem um perfil mais institucional e as produções, mesmo que estejam ali colocadas, nem sempre são o foco do portal ou plataforma. Observa-se que mesmo com a pretensão de divulgação de trabalhos mediante outras modalidades narrativas e/ou linguagens, ainda existe uma forte ligação dos laboratórios com a dimensão textual pelos espaços destinados à divulgação de texto e livros temáticos e/ou produções. 
Apesar de ser uma prática destinada à divulgação de produções e acervos, nos sites e plataformas consultados, pouca ou nenhuma referência é colocada como sendo vinculadas ao campo da História Pública. Isso não significa que esteja ausente nas reflexões resultantes desta perspectiva de posicionamento sobre a memória e a história. No caso da disponibilização de acervos, em alguns casos, como o do Laboratório de História Oral da UFSC, encontram-se referenciados de forma muito simples, impossibilitando o acesso a distância ou o conhecimento prévio sobre o que se encontra disponível.

Ao mesmo tempo em que se buscou esse levantamento, revisões bibliográficas e discussões em grupos de estudos foram fundamentais para compreendermos conceitos utilizados na pesquisa, a exemplo da definição de “História Digital”. Segundo Oliveira (2014, p. 09)

Nos Estados Unidos, o surgimento da chamada Digital History pode ser localizado nos anos 90, quando no Center For History and New Media (CHNM) da Universidade George Mason foram desenvolvidos projetos na área das novas mídias. Neste espaço, foram pensadas propostas em prol da preservação do passado, através de iniciativas que usavam tecnologias de informática que buscavam democratizar o acesso e a manipulação de conteúdos históricos na internet.

Para melhor compreendermos esse campo de referência, também foi importante utilizar categorias articuladas à mídia digital e seus estudiosos, entres os quais destaca-se a "Cultura Participativa". Após o avanço da web 2.0 e a expansão de sua utilização e influência nas redes sociais em nosso cotidiano evidenciam-se novos usos dos meios virtuais para divulgação e atualização de informações. Em outras palavras, nesse processo ocorreu o surgimento de um efetivo compartilhamento de mídia pela visualização e acesso de informações e, especialmente pela manifestação de opiniões em formação sobre temas diversos. Assim, percebe-se um crescente movimento de "uma variedade de grupos que funcionam na produção e na distribuição de mídia para atender a seus interesses coletivos, de modo que diversos especialistas interligaram suas análises do fandom num discurso mais abrangente sobre a participação na mídia e por meio dela." 
(JENKINS; GREEN; FORD. 2014). A utilização de portais, como o YouTube, pelos laboratórios serviriam não apenas como repositórios e reprodutores em suas produções, mas também como ferramenta de compartilhamento, debate e interação que rompeu barreiras territoriais e permitiu inclusões transnacionais. Outro conceito destacado e utilizado nesta pesquisa foi a própria concepção de "História Pública", uma vez que direcionava nossa perspectiva quanto a averiguar como os laboratórios vinham trabalhando com esse campo em ascensão no Brasil:

uma possibilidade não apenas de conservação e divulgação da história, mas de construção de um conhecimento pluridisciplinar atento aos processos sociais, às suas mudanças e tensões. Num esforço colaborativo, ela pode valorizar o passado para além da academia; pode democratizar a história sem perder a seriedade ou o poder de análise. Nesse sentido, a história pública pode ser definida como um ato de "abrir portas e não de construir muros". (ALMEIDA; ROVAl; 2011. p. 07)

Deste modo, estendemos nossa reflexão da pesquisa aplicada no campo da história às relações existentes quanto à produção histórica nos meios acadêmicos diante de seus públicos, observando como as instituições de ensino superior estão buscando adaptar-se nos ambientes voltados a produzir e difundir novas narrativas diante das demandas sociais do tempo presente.

\section{Sobrevoando Laboratórios relacionados à Imprensa no Brasil: estudos e} reflexões

Durante o período de levantamento de sites e plataformas, verificamos também a existência de Centros de Memória. Entre estes, identificamos três que possuíam como foco principal uma sessão e/ou linha de pesquisa dedicada ao tema da História da Comunicação. Na sequência, uma breve descrição sobre cada um buscando, ao final, uma análise comparativa.

O primeiro caso é o Laboratório de História Oral e Imagem da Universidade Federal Fluminense (LABHOI/UFF). Coordenado pela professora Hebe Mattos, o site do 
laboratório possui um layout claro e atrativo à primeira vista. As linhas de pesquisa do laboratório, que definem o formato pelo qual o site é organizado, são unidas pelo eixo comum dos estudos sobre memória, conforme citado: “Memória, África, Escravidão”; “Memória, Artes, Mídias"; e, “Memória, Cidade, Comunidade”. No caso do eixo “Memória, Artes, Mídias”, segundo declarado no site do Laboratório,

\begin{abstract}
A linha se organiza em torno de uma história da arte como história da imagem, assumindo o conceito de cultura visual como referência ao enfatizar o estudo das práticas do olhar e da produção de sentidos nas sociedades contemporâneas através das mídias visuais e sonoras. Desenvolve também investigação sobre imprensa, fotografia, cinema, rádio e televisão, compreendidos como dispositivos de mediação cultural e agenciadores de culturas políticas. Neste sentido, interessa-se por desenvolver estudos voltados para a identificação dos mediadores culturais e análise do circuito social das mídias (produção, circulação, consumo e agenciamento), dimensionando seu papel na construção da memória social contemporânea. (SITE DO LABORATÓRIO DE HISTÓRIA ORAL E IMAGEM, 2016)
\end{abstract}

Articuladas à linha, existem cinco projetos de pesquisa que podem ser acessados nos links e que contam com maiores detalhes seus focos, objetivos, coordenadores e produções. É interessante notarmos que destes, apenas um possui recorte temporal anterior ao século XX, sendo então esse período o foco de estudos dessa linha. Até o último acesso ( ${ }^{\circ}$ de Março de 2015), os projetos de pesquisa apresentados eram os seguintes: "O Olhar Engajado: Prática Fotográfica e os Sentidos da História, Brasil 19601990"; “Memórias do Contemporâneo: narrativas e imagens do fotojornalismo no Brasil do século XX"; "Imagens Urbanas no Brasil: escultura pública e grafite urbano contemporâneo"; "Sentidos da Americanidade: Conferências Interamericanas e Esculturas Públicas Americanas na Cidade do Rio de Janeiro"; e, "Sentidos da arte estrangeira no Brasil".

Com excessão dos dois últimos projetos, todos os demais possuem produções em vídeo, acervo de imagens e sons, além de gravações de entrevistas e produções de livros temáticos apontando para o interesse efetivo do laboratório e da linha na produção, além de textos e textualidades como pretendíamos verificar inicialmente. 
O site, como um todo, possui acervos digitais ricos tanto na área de história da imagem quanto na área de História oral. No caso das entrevistas, estas são disponibilizadas também de maneira integral para consulta e estudo de pesquisadores interessados. No caso do LABHOI/UFF, observamos que as produções estão muito ligadas à questão da imagem, tendo a fotografia e o fotojornalismo como principal foco de investigação.

O segundo caso escolhido para observação neste artigo foi o Centro de Documentação e Memória Social DELFOS (PUC/RS). Por definição, um Centro de Documentação caracteriza-se, atualmente, em oposição aos Arquivos. Seriam “estruturas que se organizam a partir da idéia de coleção, dada sua natureza de agrupamento a priori, subjetiva e artificial" (SILVA, 1999. p. 89).

Criado em 2007, mas inagurado apenas em 2008, o DELFOS tem por objetivo

a promoção da cultura e a preservação da memória no que diz respeito aos documentos doados ao Espaço. O acervo é composto por documentos ligados à cultura gaúcha ou a escritores, entidades ou autoridades representativas para o Estado do Rio Grande do Sul. O Espaço preserva, acondiciona e disponibiliza a pesquisadores cadastrados os documentos confiados ao Delfos. (Disponível em: SITE DO DELFOS - ESPAÇO DE DOCUMENTAÇÃO E MEMÓRIA CULTURAL, 2016)

No portal do Centro, verificam-se diversas coleções, especialmente as ligadas a acervos de Escritos, Historiadores, Jornalistas e Arquitetos. Nesse trabalho nos concentraremos na seção de "jornalistas e escritores", que documentam a experiência de 26 figuras importantes no cenário gaúcho e nacional, a exemplo de Caio Fernando de Abreu.

Ao selecionar a figura que se pretende ter acesso à documentação, o visitante ou pesquisador, abre uma página no portal dedicada apenas àquela pessoa e onde encontra uma breve biografia, que inclui as suas produções, um banco de imagens (se existem!) e um catálogo de fontes digitalizadas e depositadas em um repositório digital. Um ponto interessante é que o centro ainda organiza uma cronologia dos momentos mais 
marcantes da vida da pessoa, tentando criar uma rápida biografia em conjunto com outros dados citados. O DELFOS ainda possui um acervo de imagens da revista O Globo.

Pensando uma análise relativa às produções não textuais e narrativas escritas, verificamos que não existe uma preocupação com essa questão sendo a palavra e o texto o principal foco de produção do Centro. Não foram identificadas, como ocorre no caso do LABHOI, produções de documentários ou entrevistas orais gravadas e disponibilizadas na íntegra para consulta, estudo ou qualquer outro fim.

O último portal selecionado não pertence propriamente a uma instituição acadêmica específica e foi analisado exclusivamente para este trabalho. O Centro de Cultura e Memória do Jornalismo foi criado em 2008, pelo Sindicato dos Jornalistas Profissionais do Município do Rio de Janeiro e patrocinado pela Petrobrás.

Da mesma forma que a imprensa é um dos pilares essenciais da democracia, preservar e registrar sua história éenriquecer a própria memória coletiva dos brasileiros. Daí a importância do projeto de criação do Centro de Cultura e Memória do Jornalismo do nosso país.

A Petrobras, mais do que apoiar essa iniciativa, é sua parceira. Afinal, a empresa foi criada no bojo daquela que possivelmente tenha sido a maior mobilização popular da história brasileira - a campanha "O petróleo é nosso" - e, desde então, tem profunda consciência da importância vital da imprensa. Sem o debate público propiciado pelos jornais da época, outra seria a nossa história.

Maior empresa brasileira e maior patrocinadora das artes e da cultura em nosso país, a Petrobras põe ênfase especial em projetos que se destinem a preservar e difundir a memória da sociedade brasileira. Uma imprensa livre e soberana merece ter sua história preservada e conhecida. ( SITE DO CENTRO DE CULTURA E MEMÓRIA DO JORNALISMO, 2016)

Este portal é dedicado especialmente a disponibilizar fontes relativas à história do jornalismo em formato digitalizado ou, ainda, através de transcrições de entrevistas. Partindo deste ponto, notamos novamente o forte apego ao uso das textualidades. 


\section{Refletindo os três casos: algumas considerações finais}

Em um exercício comparativo, podemos verificar que na observação dos três casos estudados evidencia-se o apego às textualidades como predominante. Talvez por se tratar de um espaço de memória vinculado à prática da historiografia com alguma proximidade junto aos debates da História Pública, ou por se tratar de um local de guarda de acervo junto à prática investigativa , o LABHOI/UFF apresenta um portal que permite o acesso a conteúdos de mídias mais diversificados e interativos. Como destaca Bresciano (2010), entre outros fatores, a associação entre História Oral e os meios digitais são importantes, pois,

(iv) La conformación de repositorios digitales que conservan fuentes específicas para la Historia Oral supone una modalidad original de relacionamiento entre el investigador y los archivos, la cual redunda en una mayor eficiencia en las compulsas documentales.

(v) La generalización de portales telemáticos destinados a la divulgación de centros y de archivos que cultivan la oralidad estimula el acceso generalizado a cierta clase de fuentes orales y fomentan el intercambio académico más allá de fronteras geográficas. (BRESCIANO, 2010. p. 2)

Os outros dois portais estão mais voltados para os trabalhos de disponibilização de fontes do que para o exercício da pesquisa. É importante destacarmos que o LABHOI/UFF foi tomado como parâmetro inicial para o desenvolvimento desta pesquisa por ser considerado um dos primeiros exemplos institucionais com tais características no país.

Com relação à presença de historiadores e participantes, constata-se que apenas o LABHOI/UFF e o Delfos (PUC/RS) possuem uma preocupação em elucidar os membros da equipe, enquanto o portal Centro de Cultura e Memória do Jornalismo apenas faz referência ao vínculo de um projeto sindical. Já a questão da visualidade, como se apresentam os portais, novamente cabe o destaque às regiões Sul e Sudeste, pela apresentação de um layout mais desenvolvido e leve, não dependente, por exemplo, de suportes, como o YouTube, ao disponibilizar fontes e acervos. 


\section{Referências}

ALMEIDA, Juniele Rabêlo de; ROVAI, Marta Gouveia de Oliveira. Apresentação. In: ALMEIDA, Juniele Rabêlo de; ROVAI, Marta Gouveia de Oliveira (Org.). Introdução à história pública. Florianópolis: Letra e Voz, 2011. p. 7-15.

BARBOSA, Marialva. Como construir uma história da imprensa. In: ENCONTRO DA REDE ALFREDO DE CARVALHO, II. 2004, Florianópolis. Florianópolis: UFSC, 2004.

BRESCIANO, Juan Andrés. La historia oral en contextos digitales. Transgormaciones recientes de un subcampo disciplinario. In: História Oral, v. 13, n.2, p. 11-31, jul.-dez., 2010.

CAPELATO, Maria Helena.O bravo matutino: (imprensa e ideologia o Jornal O Estado de S. Paulo). São Paulo: Alfa-Omega, 1980.

HARTOG, François. Regimes de historicidade: presentismo e experiências do tempo. Belo Horizonte: Autêntica, 2014.

JENKINS, Henry; GREEN, Joshua; FORD, Sam. Cultura da conexão: criando valor e significado por meio da mídia prorrogável. São Paulo: Aleph, 2014.

KOSSELLECK, Reinhardt. Futuro passado. Rio de Janeiro: Contraponto, 2006.

LE GOFF, Jacques. História e memória. Campinas, SP: Editora da UNICAMP, 2003.

OLIVEIRA, Nucia Alexandra Silva de. História e internet: conexões possíveis. Revista Tempo e Argumento, Florianópolis, v. 6, n.12, p. 23 - 53, maio/ago., 2014.

SILVA, Zélia Lopes da. O Centro de Documentação e Apoio à Pesquisa, um centro de "Memória" local? In: SILVA, Zélia Lopes da (Org.). Arquivos, patrimônio e memória: trajetórias e perspectivas. São Paulo: Unesp, 1999. p. 85-95.

SITE DO LABORATÓRIO DE HISTÓRIA ORAL E IMAGEM. Local: LABHOI/UFF), 2016. Disponível em: <http://www.labhoi.uff.br/>. Acesso em 20 de Maio de 2016.

SITE DO CENTRO DE CULTURA E MEMÓRIA DO JORNALISMO.LOCal: CCMJ, 2016 Disponivel em: <http://www.ccmj.org.br/sobre-o-centro/parceiros>. Acesso em 23 de Março de 2016.

SITE DO DELFOS - ESPAÇO DE DOCUMENTAÇÃO E MEMÓRIA CULTURAL.Local: PUCRS, 2016.Disponível em <http://www.pucrs.br/delfos/>. Acesso em 20 de Maio de 2016. 
Recebido em: 02/06/2016 Aprovado em: 06/09/2016

Universidade do Estado de Santa Catarina - UDESC

Centro de Ciências Humanas e da Educação - FAED

Revista PerCursos

Volume 17 - Número 34 - Ano 2016 revistapercursos@gmail.com 